\title{
Designing, Prototyping and Evaluating Digital Mindfulness Applications: A Case Study of Mindful Breathing for Stress Reduction
}

Bin Zhu ${ }^{1,2}$; Anders Hedman ${ }^{1}$, PhD; Shuo Feng ${ }^{1}$; Haibo Li ${ }^{1}$, PhD; Walter Osika ${ }^{3}, \mathrm{MD}, \mathrm{PhD}$

\footnotetext{
${ }^{1}$ School of Computer Science and Communication, KTH Royal Institute of Technology, Stockholm, Sweden

${ }^{2}$ School of Film and Animation, China Academy of Art, Hangzhou, China

${ }^{3}$ Department of Clinical neuroscience, Karolinska Institutet, Stockholm, Sweden
}

Corresponding Author:

Bin Zhu

School of Computer Science and Communication

KTH Royal Institute of Technology

Lindstedtsvägen 3

Stockholm, 10044

Sweden

Phone: 46723068282

Fax: 4687909099

Email: binz@kth.se

\section{Abstract}

Background: During the past decade, there has been a rapid increase of interactive apps designed for health and well-being. Yet, little research has been published on developing frameworks for design and evaluation of digital mindfulness facilitating technologies. Moreover, many existing digital mindfulness applications are purely software based. There is room for further exploration and assessment of designs that make more use of physical qualities of artifacts.

Objective: The study aimed to develop and test a new physical digital mindfulness prototype designed for stress reduction.

Methods: In this case study, we designed, developed, and evaluated HU, a physical digital mindfulness prototype designed for stress reduction. In the first phase, we used vapor and light to support mindful breathing and invited 25 participants through snowball sampling to test HU. In the second phase, we added sonification. We deployed a package of probes such as photos, diaries, and cards to collect data from users who explored $\mathrm{HU}$ in their homes. Thereafter, we evaluated our installation using both self-assessed stress levels and heart rate (HR) and heart rate variability (HRV) measures in a pilot study, in order to measure stress resilience effects. After the experiment, we performed a semistructured interview to reflect on HU and investigate the design of digital mindfulness apps for stress reduction.

Results: The results of the first phase showed that 22 of 25 participants (88\%) claimed vapor and light could be effective ways of promoting mindful breathing. Vapor could potentially support mindful breathing better than light (especially for mindfulness beginners). In addition, a majority of the participants mentioned sound as an alternative medium. In the second phase, we found that participants thought that $\mathrm{HU}$ could work well for stress reduction. We compared the effect of silent HU (using light and vapor without sound) and sonified HU on 5 participants. Subjective stress levels were statistically improved with both silent and sonified HU. The mean value of HR using silent HU was significantly lower than resting baseline and sonified HU. The mean value of root mean square of differences (RMSSD) using silent HU was significantly higher than resting baseline. We found that the differences between our objective and subjective assessments were intriguing and prompted us to investigate them further.

Conclusions: Our evaluation of HU indicated that HU could facilitate relaxed breathing and stress reduction. There was a difference in outcome between the physiological measures of stress and the subjective reports of stress, as well as a large intervariability among study participants. Our conclusion is that the use of stress reduction tools should be customized and that the design work of mindfulness technology for stress reduction is a complex process, which requires cooperation of designers, HCI (Human-Computer Interaction) experts and clinicians.

(J Med Internet Res 2017;19(6):e197) doi: 10.2196/jmir.6955 


\section{KEYWORDS}

respiration; biofeedback; mindfulness; stress; device design; sound; light; breathing; heart rate; relaxation

\section{Introduction}

High levels of stress and information overload are increasingly contributing to the global burden of disease [1,2] at great societal costs. For example, in Europe, the total costs of mental health disorders are estimated to be $€ 240$ billion per year [3], and globally the costs are most certainly much higher. There is therefore an urgent need for both preventive interventions aimed at reducing the adverse effects of stress, taking into account biological, psychosocial, and environmental risk factors, as well as new effective treatment strategies.

The human stress response is partially mediated through the autonomic nervous system (ANS), divided into the sympathetic and parasympathetic systems. The majority of our internal organs are, directly or indirectly, controlled through these systems. The sympathetic system prepares us for dangerous situations and triggers the stress response. The parasympathetic system governs rest and digestion [4]. High levels of stress and prolonged stress without recuperation result in cognitive, emotional, and somatic symptoms [5-7].

Western stress reduction methods have lately been CBT-oriented (building on insights from Cognitive Behavioral Therapy), with mechanistic approaches, and have emphasized behavioral changes. Eastern meditative traditions have in contrast focused more on present-centered attention and awareness, that is, what has been termed mindfulness in the West [8,9], and non-judgmental acceptance of encountered life situations. Practicing compassion and selflessness in search of balance and resilience, appreciation of life and nature in a fluid and dynamic state of constant imbalance are also major topics of eastern meditative traditions such as Buddhism [10]. Balance and resilience can be achieved through the self-healing capacity of individuals particularly when confronting stress and adversity [11]. Eastern meditative approaches have been deployed for stress reduction in westernized contexts, for example, through the practice of tai-chi $[12,13]$, Qigong [14,15], and mindfulness $[16,17]$.

Drawing on eastern meditative traditions, mindfulness-based stress reduction (MBSR) [18] has been proven effective for reducing stress and anxiety, and is currently one of the most researched treatment packages [19-25]. MBSR is based on procedures to establish increased awareness of moment-to-moment experience and develop compassionate non-judgmental acceptance of oneself, others, and encountered life situations. With digital technologies potentially revolutionizing health and well-being, people increasingly turn to technology to handle stress, anxiety, social isolation, and negative emotions [26-28]. Conventional mindfulness practice is moving to digital devices that potentially can support people's needs in the digital age $[29,30]$. New partnerships among psychologists, social scientists, designers, and engineers are needed to better understand the psychological and behavioral impact of these new technologies and applications [31].
In this paper, we focus on designing digital technology for MBSR, in particular, mindful breathing. Mindful breathing can be defined as calm and conscious deep breathing and is a cornerstone of MBSR [32]. We are often unaware of how we breathe and when stressed we breathe in shallow, tensed ways that furthers the stress. "Take a deep breath" is one of the first things we are likely to say to someone deeply anxious. We intuitively know that calm and deep (abdominal) breathing does us good. Can we support such healthy breathing patterns through technology? This is one of the questions we explore in this paper.

Researchers have developed technologies to support relaxation breathing. Wollmann et al developed an android flight game using resonant frequency breathing to increase heart rate variability (HRV) and improve ANS balance [33]. Khut and Muller [34] designed a biofeedback-based multisensory presentation of heart and breathing rates to support self-awareness in more direct ways than traditional quantified-self-monitoring techniques provide. Khut also developed a biofeedback-based stress-relief app called BrightHearts $[35,36]$. Heart rate and breathing sensors were used to visualize interactive halos and sounds. Colors, diameters, and saturation of the halos vary according to breathing and heart rate. When one's heart rate decreases, the color changes from red to green and the pitch decreases. Researchers from Stanford University found visual feedback to be effective for supporting healthy deep breathing and that auditory feedback can further subjective feelings of calm [37]. Others found that calming nature sounds were an effective way of reducing stress in an emergency department. Negative affect scores were lower whereas positive affect scores were the same or higher for participants of a nature-sound intervention group [38] on an affect test in comparison with a control group. Vidyarthi et al [39] created a meditative display by connecting respiration to a peaceful soundscape and developed a psychological framework for media immersion. Furthermore, physical and tangible artifacts have been used with digital technologies to capture and represent respiration and bodily interaction. Influenced by somaesthetics [40], Höök and her colleagues translated experiential insights from long-term practice of Feldenkrais exercises into a design prototype called Breathing Light [41], an enclosed space for reflection utilizing body movements. Sensors measure chest movements that control a lamp so the light changes according to breathing patterns. Their somaesthetic design engaged people by increasing their awareness of internal bodily sensations rather than external processes.

Inspired by the previous studies, we have the hypothesis that interactive physical artifacts based on visual and sound feedback can support mindful breathing for stress reduction. To explore how interactive visual and sound feedback could be used to support mindful and relaxing deep breathing, we designed, developed, and evaluated HU (Figure 1), a physical digital mindfulness prototype based on vapor, light, and sound. HU is a sonified vapor diffuser that expels vapor and emits sounds according to systematic relations with a meditator's heart rate. 
We think of these relations as isomorphic and tunable. They are relations among heart rate, vapor expulsions and sounds, subject to experimentation and tuning through user feedback As a device for supporting mindful breathing, HU could come to function as a part of MBSR interventions.

The paper is structured as follows: First, we look at stress and stress management from scientific and contemplative perspectives, focusing on MBSR. Second, we account for how we developed HU to support mindful breathing for well-being. Third, we describe how users experience HU, as well as how using $\mathrm{HU}$ affects them physiologically and psychologically with respect to stress resilience. Finally, we discuss our conclusions and possible directions for future work.

Figure 1. HU: a case study of mindful breathing for stress reduction.

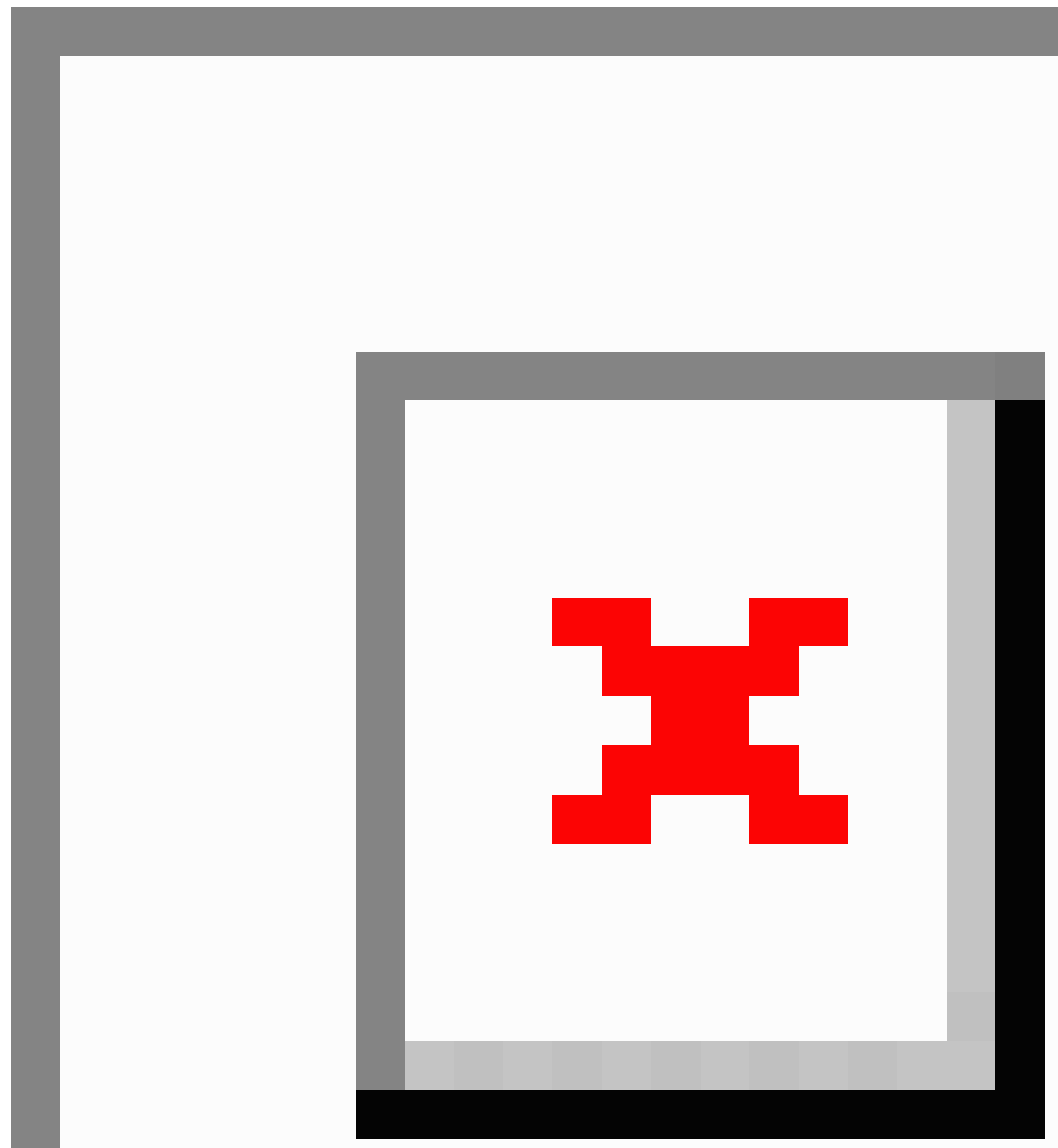

\section{Methods}

\section{Study Design}

We applied the Research through Design (RtD) method [42] in our design process of HU. In an RtD research process, we drive the exploration of both problems and solutions. We gain new knowledge through the act of making things and iterative design work. The knowledge gained during the process can be expressed and articulated in design methods and principles. Our design process consisted of two phases. In the first, initial design phase, we used vapor and light to support mindful breathing. In the second phase, we added sonification. 


\section{Initial Design Phase: The Prototype}

The design of HU is inspired by the ancient Chinese incense furnace. In Chinese, HU means to breathe out. HU is a vapor diffuser modified with biosensors. HU measures the heart rate with an earlobe sensor (Figure 1) and supports resonant frequency breathing through vapor pulses. Resonant frequency breathing is a specific biofeedback training strategy based on resonance properties of the cardiovascular system $[43,44]$. Resonant frequency breathing can be effective in furthering relaxation and homeostatic balance [43]. HU expels vapor to support resonant frequency at $0.1 \mathrm{~Hz}$ (6 breaths/minute) [43,45]. The light of HU is adapted with the meditator's heart rate through the brightness. Fast heart rates are bright and slow heart rates dim.

Figure 2. HU prototype.

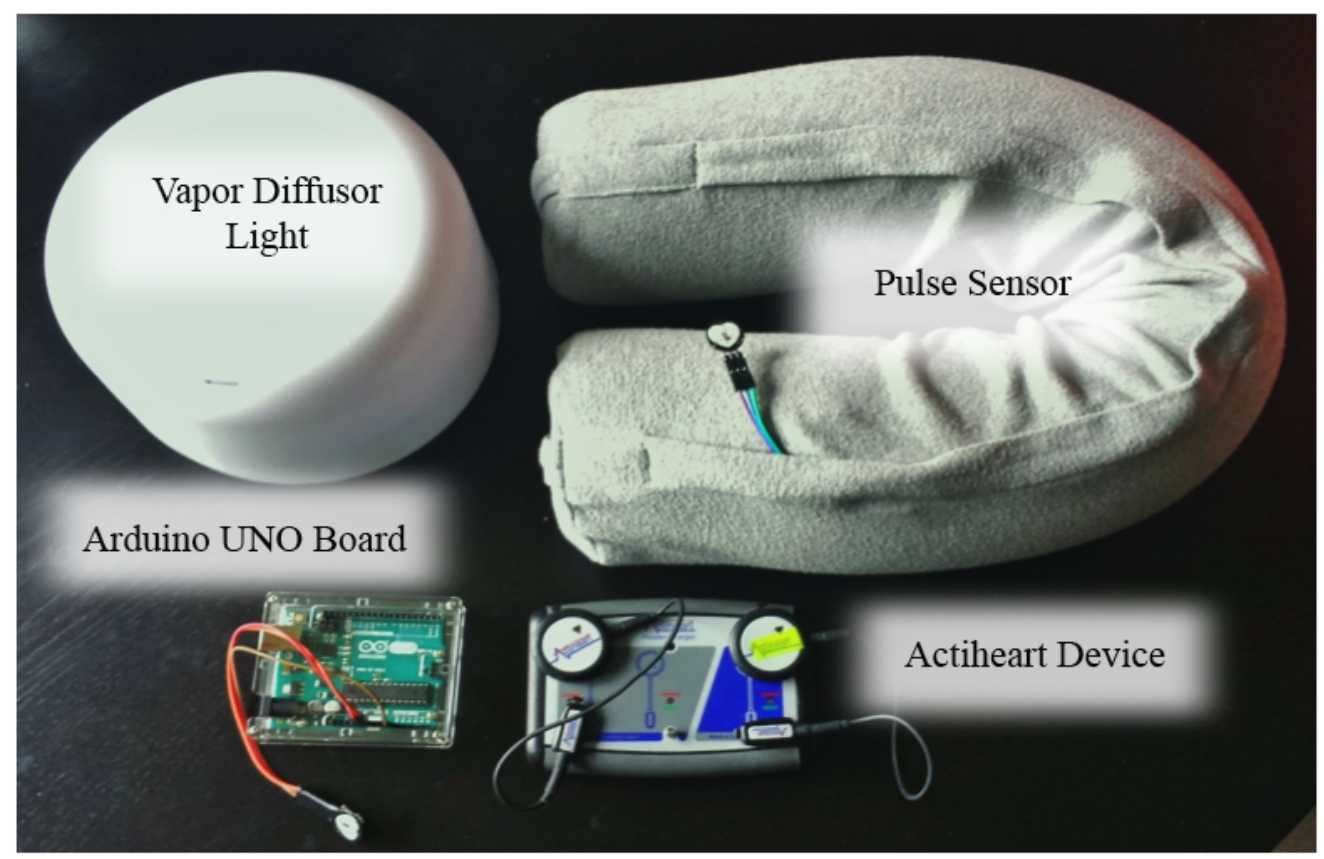

\section{Initial Design Phase: Evaluation}

We investigated how HU could support mindful deep breathing through a meditation intervention. We selected 25 participants through snowball sampling [46], of which 12 were males and 13 were females. The ages ranged between 23 and 60. They were originally from Sweden (10), China (7), Spain (2), the United States (2), the United Kingdom (1), Italy (1), and Australia (1), and all lived in Sweden. They represented a range of occupations including teachers, students, engineers, doctors, office workers, and mindfulness coaches. Among the 25 participants, 15 lacked the experience of mindfulness or meditative practice; 5 were beginners; and the remaining 5 were experienced mindfulness meditators. We arranged the $\mathrm{HU}$ in a quiet room and asked participants to try it for 10-20 min, and then interviewed them. The participants were interested in $\mathrm{HU}$ and enjoyed engaging with HU to support mindful breathing. About 22 of the 25 participants $(88 \%)$ claimed that vapor can lead to mindful breathing and helped them relax. The meditators regarded the vapor as a good component for 4 reasons:

1. Rhythmically tuned vapor pulses can support synchronized deep breathing.

2. Vapor is aesthetically pleasing.

3. Fleeting vapor reflects the fleeting present.

4. Vapor is subtle and non-distractive.
Three meditators, however, thought vapor failed to support mindful breathing. Two of them lacked experience with mindfulness and claimed it was difficult to follow the vapor while focusing on their breath. One of them was a mindfulness coach who had practiced mindfulness for 10 years. She focused better on her "inner being" without the vapor.

Fifteen participants saw the light as a good way to enhance the experience of interaction. Light was regarded as a good medium mainly for three reasons:

1. It is visually pleasing and evokes enjoyment.

2. It enriches the breathing practice.

3. It supports body awareness.

Five participants disliked the light. They felt the connection between the light and heart rate was ambiguous and unclear. Three of them felt the light (in particular, the brightness indicating high heart rate) was stressful. Two mentioned that the rapidly changing light distracted them.

The results from the trial suggested that vapor and light can be effective ways of promoting mindful breathing, but that vapor could potentially support mindful breathing better than light (especially for mindfulness beginners). Finally, we found that, interestingly, a majority of the participants mentioned sound as an alternative medium for mindful breathing. Further to this, 
13 participants closed their eyes during the trial, which indicated why sound might seem so natural.

\section{Sonified Design Phase: The Prototype}

According to our meditation intervention feedback, we supplemented HU with sound. Sound can reduce stress [47,48]. Humans normally respond with affect to rhythmical sound [49], and rhythmical sound can in turn influence human behavior [50,51]. Sound can have positive psychological and physiological effects on illness [52-56]. Modern nursing pioneer Florence Nightingale noted that wind instruments, the human voice, and stringed instruments helped patients recover [57]. Alvarsson et al investigated the way sounds of nature affected subjects physiologically and psychologically [58]. Forty trial subjects were exposed to a "sounds of nature" or a "noisy" environment after performing stressful mental arithmetic. The results demonstrated that people recovered faster from sympathetic activation in the "sounds of nature" environment. Another study suggested that a natural environment had restorative effects on patients, including more positive emotions [59] and less mental fatigue [60].

We selected suitable soundtracks from a natural environmental sound database and a music database for our prototype. The prototype has two parts: a hardware prototype and a software application. The core of our hardware prototype (the sense and control unit) includes an Arduino UNO board and a pulse sensor. Heart rate data can be collected via the pulse sensor and transmitted to the Arduino UNO board. Arduino is an open source integrated programming environment [61]. The software is an audio application running on a PC developed using Pure Data, a real-time, graphical, dataflow programming application [62]. The software prototype enabled sound to be coupled with the meditator's heart rate, so tempo and sound volume increased and decreased synchronously with heart rate. We offered three sound themes:

1. Breathing: A female breathing sound

2. Nature: Rhythmical ocean waves

3. Music: Half Moon Serenade (meditation music)

People could choose sound themes freely.

\section{Sonified Design Phase: Evaluation}

We used two approaches to evaluate HU: an exploration study and an experiment. Here, we name HU without sound as silent $\mathrm{HU}$ to distinguish it from sonified HU.

\section{Exploration Study}

To study an everyday-use scenario, the experiment was conducted in the participant's homes (Figure 3). In the exploration stage, participants used $\mathrm{HU}$ for 2 days, in accordance with their own likings. During this stage, they described their experiences through diaries, photos, and short videos (of how and where they used HU). The diaries captured use conditions, including time, place, and duration, as well as experiences before and after use. To understand sound preferences for relaxation, we used picture cards on which participants attached premade cartoons to indicate their choices (Figure 4).

Figure 3. Trial photos in the context.

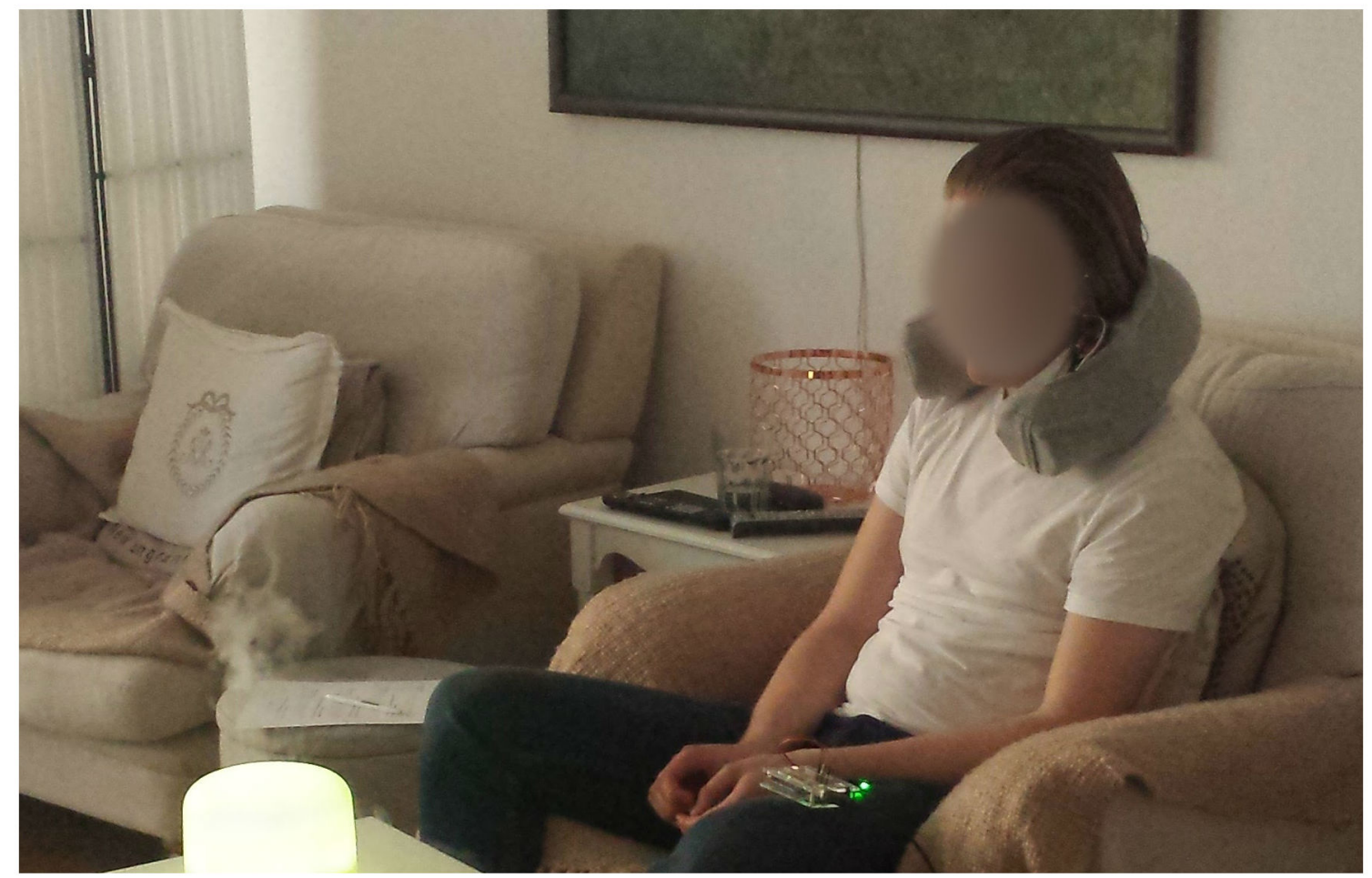


Figure 4. Picture cards.

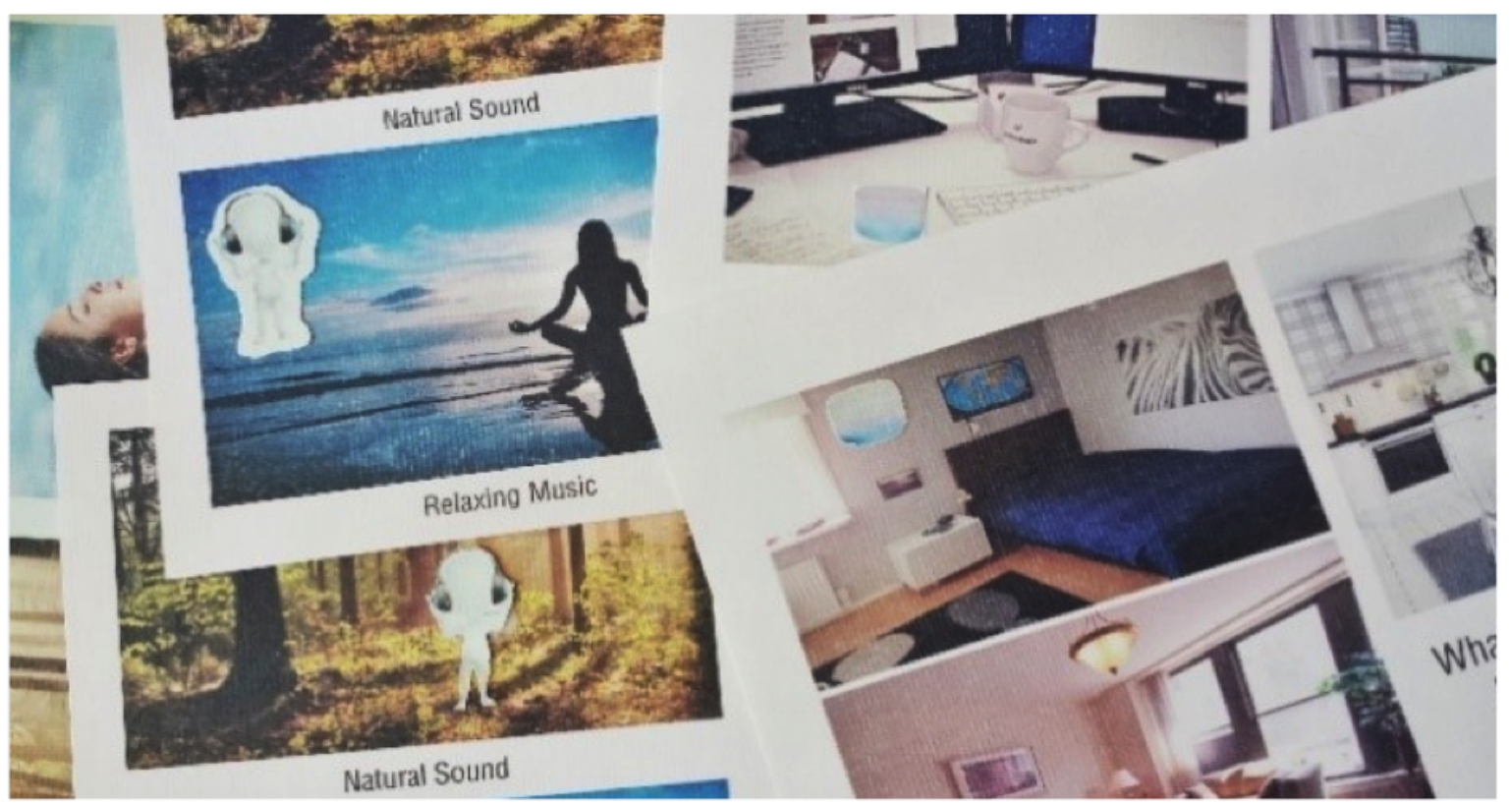

Figure 5. The procedure of the test.

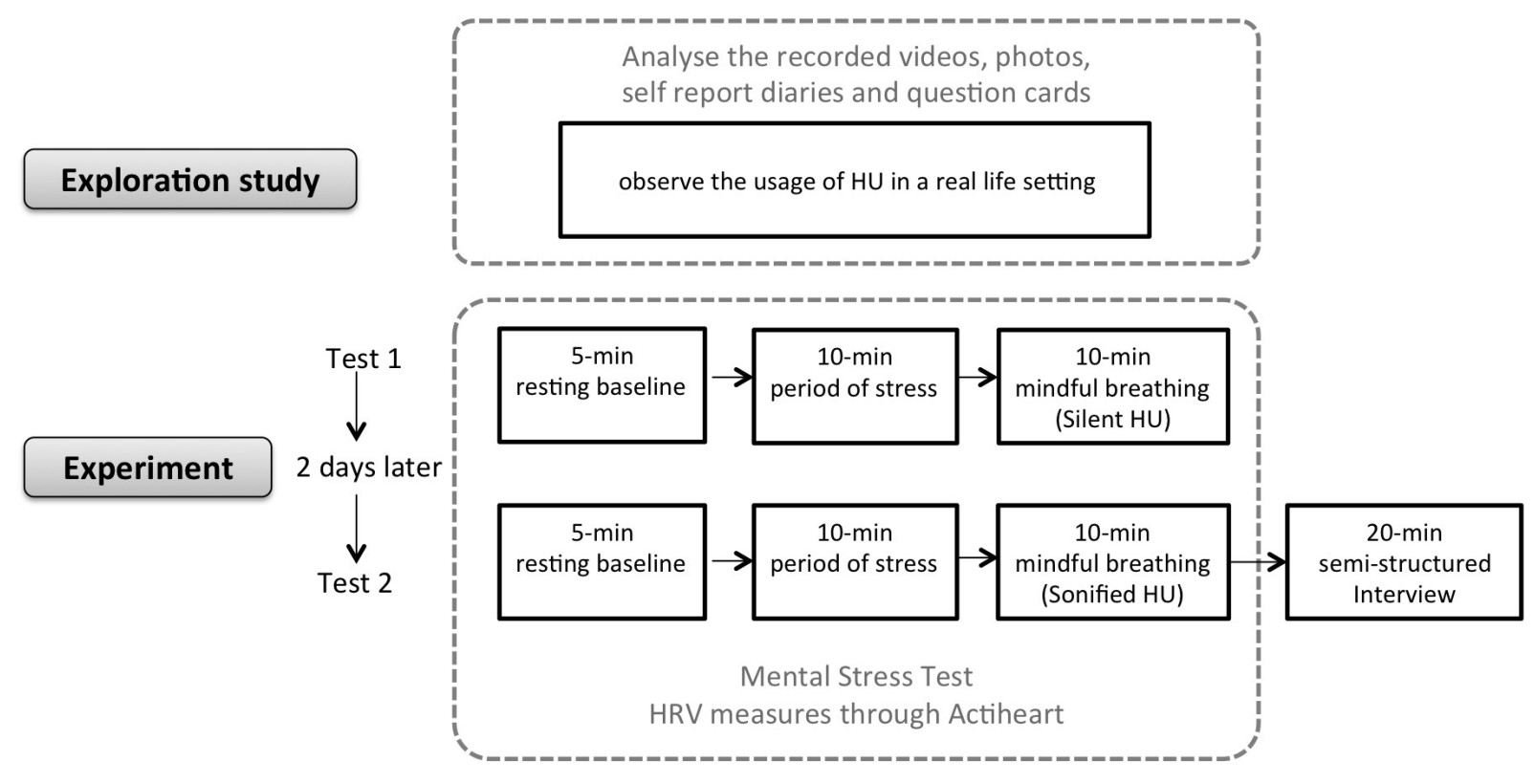

\section{Experiment}

We conducted an experiment to discern how HU could help reduce stress through mindful breathing and evaluated the outcome through self- assessment and HRV measures.

\section{Measures}

\section{Mental Stress Test}

A mental stress test was used as a stress provocation, building on earlier research with mental stress experiments [63]. We used a 10-min mental arithmetic test from the Wechsler Adult Intelligence Scale (WAIS) [64], as for example, the Trier social stress test [65] did not work in our setting. Some research has been performed on the stress inducing effects of WAIS [66-68].

\section{Visual Analogue Scale (VAS) for Subjective Stress Assessment}

Visual analogue scales (VAS) are often used for assessing subjective stress levels [69-71]. Our participants marked how stressed they felt on a $10 \mathrm{~cm}$ long line, where zero distance from the left=No stress, $5 \mathrm{~cm}=$ Neutral, and $10 \mathrm{~cm}=A s$ bad as it could be. 


\section{HRV Measurements}

HRV is the variability of intervals between consecutive heartbeats. It is regarded as a performance indicator of autonomic heart rate regulation and ANS balance [72]. High HRV is associated with a well-balanced ANS, whereas low HRV is associated with chronic stress and diseases such as diabetes and depression [73-75]. HRV has also been used as a measure of mental stress reactivity over short time periods. Troubat et al found that mental stress during short periods was associated with decreased mean HRV [76]. Researchers have sought methods for restoring normal HRV to achieve balance in the ANS [77].

HRV measures are usually divided into two categories: time domain measures and frequency domain measures. One commonly used time-domain measure root mean square of differences (RMSSD) between successive rhythm-to-rhythm (RR) intervals describes short-term HRV. In a study among employees of an electronics company, researchers found that RMSSD value is associated with perceived mental stress [78]. A low value indicates high stress.

Frequency domain method takes into account different frequency components of HRV. The two main frequency components that represent ANS activity are the low-frequency (LF) components $(0.04-0.15 \mathrm{~Hz})$ and the high frequency (HF) components (0.15-0.4 Hz). The LF band reflects sympathetic activity and the HF band, the parasympathetic activity. The ratio of LF to HF power (LF:HF) has been used to calculate and assess the sympathovagal balance for indicating the function of the ANS activity $[79,80]$.

The Actiheart device (CamNtech, UK) [81] was used for data sampling and primary data analysis in our study. It is a compact, chest-worn monitoring device that records heart rate, interbeat interval (IBI), and physical activity in one combined, lightweight waterproof unit. In the time domain analysis of HRV, the information of inter-beat interval in each measurement period was computed. In the frequency domain analysis, spectral analysis was performed.

\section{Recruitment}

Five new participants were recruited through word of mouth (3 males and 2 females, mean age 23 years). All participants were from universities in Sweden, with normal vision and hearing. Before the test, we gathered basic demographic information and their individual assessments of stress levels for the last week. The participants signed consent forms and allowed us to use their data. We used a within-subject design to evaluate silent $\mathrm{HU}$ and sonified HU, respectively. As perceived stress and HRV varied from individual to individual, a within-subject design was selected to reduce error variance associated with individual differences [82].

\section{Procedure}

Figure 5 shows the test procedure schematically. The experiment comprised 3 sessions:

1. 5-min resting baseline: Participants wore Actiheart and sat in a comfortable position as their resting baseline HRV was sampled.
2. 10-min period of stress: In order to observe the effect of using $\mathrm{HU}$ for stress reduction, we triggered a stress response in participants before the mindful breathing task. The stress-generating task was the 10-min IQ test from the Wechsler Adult Intelligence Scale (WAIS), described above.

3. 10-min mindful breathing with HU: HU was used to guide mindful breathing for $10 \mathrm{~min}$. In a first test, participants used silent HU in the mindful breathing period. After 2 days, they used sonified HU in a second test.

During the tests, participants sat in an undisturbed environment. Heart rate, RMSSD, HF, and LF were measured through the Actiheart device (Figure 2). The visual analog scale described earlier was used for assessing subjective stress levels after each session of the test.

After the experiment, we performed a semistructured interview with questions organized in 3 sections. The first section contained questions about the participants' ways of relieving stress in everyday life. The second section contained questions about HU that did not have to do with the sonification (eg, how they had used HU in their everyday life and whether they could relate the vapor flow or light to their heart rate). The last section explored issues related to the sonification. First, they were asked to describe their experiences with the sonification, and that whether they could relate the sound rhythms to their heart rate. Subsequently, we asked them what characters of sound (pitch, tempo, and volume) would make them comfortable, and how the sonification could be improved.

\section{Results}

\section{Sonified Design Phase: Results From the Exploration Study}

In the exploration stage, we observed the usage of HU in home settings with 5 participants as described earlier and analyzed their recorded videos, photos, and self-report diaries. The 5 participants reported different degrees of relaxation during and after engaging with $\mathrm{HU}$. Three reported that $\mathrm{HU}$ guided them to breathe mindfully.
When I used it, I know it worked with my breath and enabled me to follow it and take away my focus from the work. It makes me calm and peaceful... [P1]
I felt relaxed when I breathed with HU. After that, I studied more efficiently... [P4]

Three of them used HU in the evening and before going to bed. One preferred the morning and another chose the afternoon time for relaxation. They used HU for 10-20 min at a time. Most of them installed $\mathrm{HU}$ in their bedrooms and living rooms for mindfulness and relaxation. One used HU on a desk beside her while working. The bedroom was the most popular location for HU.

Apart from engaging with $\mathrm{HU}$ to support mindful breathing, they explored how HU, as an artifact, could fit into their daily life. To illustrate this last point, some found that HU could serve as a humidifier or ambient light, with the added benefit of enhancing calmness and relaxation. 
It just makes me feel good when $H U$ is besides me. [P2]

I like the dim yellow light and the vapor. Especially the white vapor...looks dreamy... [P3]

I used HU as a humidifier at home. It works for me...I like a multi-functional device...could be a breath machine for meditation, a humidifier or an ambient light... [P5]

In terms of the 3 interactive sound themes, 2 out of 5 participants thought nature sounds best helped them relax. They commented that the sound of water such as ocean waves could help them relax. The others believed meditation music was more relaxing. The woman's breathing sound can be used for guiding the breath but was not considered as relaxing as the other two themes.

\section{Sonified Design Phase: Results From the Experiment}

A paired $t$ test was used to evaluate the effects of using silent HU and sonified HU among the 5 participants. The HR, RMSSD, LF:HF, and subjective stress scores are shown in Table 1. The mean value of HR using silent $\mathrm{HU}$ is significantly lower than the resting baseline and sonified $\mathrm{HU}$ (63.4 vs $68.6, P=.008$; 63.4 vs $68.4, P=.03$, respectively). The mean value of RMSSD using silent $\mathrm{HU}$ is significantly higher than the resting baseline (58.734 vs 46.396, $P=.04$ ). However, the mean values of RMSSD and LF:HF during use of sonified HU showed no significant improvement compared with silent $\mathrm{HU}$ and the resting baseline. The subjective stress assessment was significantly improved in silent $\mathrm{HU}(3.1$ vs $6.54, P=.01)$ and sonified HU ( 2.9 vs $6.54, P=.01)$ compared with the resting baseline. In terms of subjective stress, there was no significant difference between silent and sonified HU $(P=.82)$.

Table 1. Mean and $t$ test scores during resting baseline and silent HU

\begin{tabular}{|c|c|c|c|c|c|c|}
\hline \multirow[t]{2}{*}{ Measures } & \multicolumn{2}{|l|}{ Baseline } & \multicolumn{2}{|c|}{ Silent HU } & \multirow{2}{*}{$\begin{array}{l}t \text { test } \\
t_{4} \\
\text { degrees of freedom }=4\end{array}$} & \multirow{2}{*}{$\begin{array}{l}P \text { value } \\
P \\
\text { significance level of } \\
.05\end{array}$} \\
\hline & Mean & Standard error & Mean & Standard error & & \\
\hline HR & 68.6 & 2.32 & 63.4 & 2.77 & 4.8702 & .008 \\
\hline RMSSD & 46.396 & 8.28 & 58.734 & 8.98 & -2.9317 & .04 \\
\hline LF:HF & 2.37 & 0.89 & 3.264 & 1.63 & -0.5512 & .61 \\
\hline Subjective stress (0-10) & 6.54 & 0.70 & 3.1 & 0.56 & 4.4278 & .01 \\
\hline
\end{tabular}

Table 2. Mean and $t$ test scores during resting baseline and sonified HU

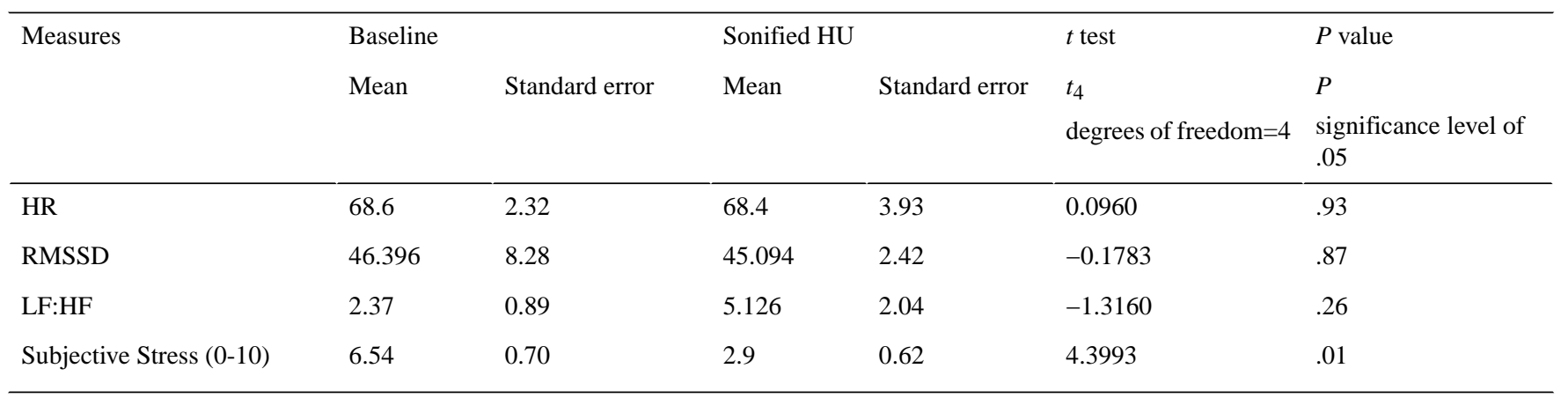

Table 3. Mean and $t$ test scores during silent HU and sonified HU

\begin{tabular}{|c|c|c|c|c|c|c|}
\hline \multirow[t]{3}{*}{ Measures } & \multicolumn{2}{|c|}{ Silent HU } & \multicolumn{2}{|c|}{ Sonified HU } & \multirow{3}{*}{$\begin{array}{l}t \text { test } \\
t_{4} \\
\text { degrees of freedom }=4\end{array}$} & \multirow{3}{*}{$\begin{array}{l}P \text { value } \\
P \\
\text { significance level of } \\
.05\end{array}$} \\
\hline & Mean & Standard error & Mean & Standard error & & \\
\hline & & & & & & \\
\hline HR & 63.4 & 2.77 & 68.4 & 3.93 & -3.2969 & .03 \\
\hline RMSSD & 58.734 & 8.98 & 45.094 & 2.42 & -1.5197 & .2 \\
\hline $\mathrm{LF}: \mathrm{HF}$ & 3.264 & 1.63 & 5.126 & 2.04 & -2.3225 & .08 \\
\hline Subjective Stress (0-10) & 3.1 & 0.56 & 2.9 & 0.62 & 0.2453 & .82 \\
\hline
\end{tabular}

We compared the measures of HR, RMSSD, LF:HF, and subjective stress during each session and analyzed the results individually (in Multimedia Appendix 1).

\section{Sonified Design Phase: Interview Findings}

P1 and P4 thought silent HU worked better than sonified HU. They declared that the visual aids were more effective than the 
auditory for relieving stress, as the vapor seemed more connected to the breath.

I think it can help me some...it was a relaxing device in that sense. I would observe the light changing for a little while and then close my eyes to relax. [P1]

I found the sound and vapor did not correspond to each other. I focused on the vapor more than the sound so that I did not notice the relationship between sounds and my bodily state. [P4]

Three more participants were also unsure about the sound and its relation to their bodies. They guessed there might be connections between the sound and their breathing or heart rate, because the music changed when they realigned their postures:

Though sometimes it was a very weird pitch of the sound, I could partly find that the sound corresponded to my breathing when I took a deep breath. [P3]

I suspect the pitch and frequency of the audio were affected by my pulse, because when my pulse was high and fast, the sound would be more rapid and at a higher pitch. [P5]

I did not know how it worked, but I sometimes found the sound to be a little bit weird and distorted. [P2]

Thus, the perceived clarity of mappings between body and visualizations and sonifications should be taken into account in designing interactive interfaces.

We asked concrete questions about the perceived effectiveness of the sonification for stress reduction. Three participants thought sound helped them ease tension and relax. One thought the interactive sound should be changed more gradually. One of them wanted to equip HU with surround sound for an immersive experience. One felt natural sounds such as wave sounds naturally helped that person better than music because of their rhythmic constancy. All thought the music should be simple, so they could focus on their breath and not on the music. Two participants found the changing tempo annoying. One of them put it this way:

Changing the tempo of the music continuously makes it weird. The music becomes distorted, and you focus on the sound. The pitch was going up and down a lot, it is better to have steady music to relax. [P2]

One participant was annoyed with the audio clips being repeated. When asked about the dynamic volume, most said they had not noticed the volume changed with their heart rate measures.

\section{Discussion}

\section{Principal Findings}

By developing and testing HU, we found that its vapor, light, and sound could enhance stress reduction. There was much interindividual variability in terms of preferred settings and modes and perceived stress reduction, and HR and HRV measures. Subjective stress levels were significantly improved with both silent and sonified HU. The mean value of HR using silent HU was significantly lower than the resting baseline and sonified HU. The mean value of RMSSD using silent HU was significantly higher than the resting baseline. However, the mean values of RMSSD and LF and HF during the use of sonified HU showed no significant improvement compared with silent $\mathrm{HU}$ and the resting baseline. In terms of subjective stress, we found no significant difference between silent and sonified HU.

How the participants perceived the mappings between heart rate and visualizations and sonifications influenced their overall experience. Regarding our interactive sound program that adjusts speed and volume according to the heart rate, there are challenges that need to be addressed. The sound tempo was not the only characteristic affected by heart rate; the pitch too was changed as a side effect. From our observations and interviews, it became clear that such pitch distortions bothered the participants. It is easy to see why: tempo and pitch play effectual and esthetic roles in music and it can be difficult to change both tempo and pitch at the same time while preserving those roles. One possible solution is to keep a slow tempo all the time. We did not test with such a noninteractive sonification, but it could be interesting to compare with in the future. Another possible solution is to use advanced sound processing, so that the pitch is preserved with tempo.

Although the sound volume varied during the experiment, participants did not notice. When we asked them about how changing the volume dynamically might enhance relaxation, they all stated that such volume changes would not affect them. It is unclear to us why sound volume did not seem to matter.

An interesting finding is that P2 and P3 felt sleepy when using HU. Participants felt calm after they used sonified HU, and most of them used HU in their bedrooms. One participant said:

\section{It makes me peaceful and sleepy. Therefore, I think it will be an excellent tool for sleep. [P2]}

HU could perhaps function as a sleep aid. HU was designed as digital mindfulness artifact, and mindfulness is commonly associated with alert wakefulness. However, most meditative traditions have incorporated measures for keeping mediators awake. It is common, for example, in many schools of Buddhism to hit meditators with a stick on their backs when they fall asleep. Zen masters often do this. As our users engaged with $\mathrm{HU}$, participants who felt sleepy were clearly able to calm down as in mindful mediation and like many other meditators this brought them closer to the sleeping state. A similar finding was reported by Britton et al, that is, that early phases of meditation may produce more fatigue and sleep propensity whereas later stages produce greater wakefulness as a result of neuroplastic changes and more efficient processing [83]. Sleepiness may not be the state that is most desirable in mindful mediation, but it seems to be a phase novice practitioners often go through. This would be interesting to explore in detail in a future study.

Another point to be discussed is the discrepancy between Actiheart measurements and subjective experience. For example, $\mathrm{P} 3$ reported feeling more relaxed in the period of sonified $\mathrm{HU}$ with a score of 0.5 compared with 3 of silent HU. However, RMSSD and LF and HF measures indicated that sonified HU was associated with more stress than silent $\mathrm{HU}$ and the resting period. The post-study interview may help us understand the 
reason for the discrepancy between subjective and physiological measures. As P3 said:

\section{I do not like that the tempo of the sound changed. If your heart rate is below your initial point, you are very relaxed. However, if your heart rate is higher than a particular point, say 79, the music you used was at very high pace, and you couldn't feel relaxed... [P3]}

There was also a discrepancy between physiological measurements and self-reported stress levels in the case of P5. P5 expressed her critical opinion on the dynamic sound:

I do not like this form of the sound. It is acceptable that the tempo is changing but not for the pitch. I also think the rhythm should not be modified a lot. [P5]

What is the right way to think about the physiological HRV measures and the self-reported stress measures? We cannot make sense of these measures without taking into account several complicated factors. One factor is for example that of the psychological situation of the test subject; it could be that the test subject is reporting feelings of relaxation while the subject is in fact not experiencing such feelings. The subject might be trying to please the experiment leader. Another factor could be sampling: perhaps the HRV equipment did not sample the signals adequately. A third factor is that the physiological and psychological measures actually might come apart, that is, they do not correspond perfectly. We hope to explore further about the relations between HRV measures and self-reported stress measures in a future follow-up study. We learned from our case study how important it is to work in a cross-disciplinary team and to make sense of the data from different perspectives. Calvo et al have stressed the significance of partnership between psychology, social sciences, and technologists [31] in the domain of human-computer-interaction for well-being. We use objective and subjective (qualitative and quantitative) approaches in terms of the assessment of mindfulness-based stress reduction. HRV measurements are commonly used in stress and medical research. These objective measures of stress are seldom used by researchers in human-computer-interaction and user experience design. The results of our study suggest we should not abandon subjective reports of user experiences. Both subjective and objective methods give valuable information. We found that the differences between the objective and subjective assessments were intriguing and prompt us to investigate them further.

\section{Limitations}

The main limitation of this study was the low number of participants. Moreover, the participants were recruited by a snowball sampling technique. To prove that sonified $\mathrm{HU}$ is effective in comparison with silent HU in improving HRV, more users would have to be recruited and according to a random sampling scheme. The participants' home environments were chosen as the experimental settings, but naturally, it is impossible to control for potentially disturbing factors in the same way that one can do in a lab or dedicated test environment.

\section{Future Work}

This study provoked greater thinking about how to design sonified devices for relaxation and mindfulness. The question of how biodata-based interactive sound could potentially reduce stress, along with the question of whether interactive sound or regular music or sounds has a more positive influence on stress reduction are topics that warrant further exploration. We plan to continue our investigations and design headphones with a pulse sensor and sound files embedded inside. A further challenge with such a device would be to incorporate HRV functionally.

\section{Conclusions}

The primary purpose of this study was to investigate whether a newly developed tool, HU, could support mindful breathing and help users reduce stress after exposure to a mental stressor. The observations, interviews, and HRV data helped us to, if not fully answer this question, explore it. Our study indicates the potential of interaction design based on vapor, light, and sound to support mindful breathing and stress reduction. Further to this, feedback from user explorations of HU in their homes and the interviews helped us understand more about the subjective experiences of using this kind of installation.

\section{Acknowledgments}

We thank all the participants of the user study. We also thank PhD Malena Ivarsson for excellent help and advice regarding the use of Actiheart.

\section{Authors' Contributions}

BZ contributed to the design of HU. SF and BZ conducted the user study and data analysis. AH, BZ, and SF drafted the paper; WO and HL reviewed the manuscript and contributed to subsequent drafts.

\section{Conflicts of Interest}

None declared.

\section{Multimedia Appendix 1}

Comparison of the measures of HR, RMSSD, LF/HF, and subjective stress during each session and individual analysis of the results. 


\section{References}

1. World Health Organization. Global action plan for the prevention and control of noncommunicable diseases 2013-2020 URL: http://apps.who.int/iris/bitstream/10665/94384/1/9789241506236 eng.pdf [accessed 2016-09-29] [WebCite Cache ID 6q5NLmSwi]

2. Bawden D, Robinson L. The dark side of information: overload, anxiety and other paradoxes and pathologies. J Inf Sci 2009;35(2):180-191. [doi: 10.1177/0165551508095781]

3. European Agency for Safety \& Health at Work. 2014. Report-Calculating the cost of work-related stress and psychosocial risks URL: https://osha.europa.eu/en/publications/literature reviews/ calculating-the-cost-of-work-related-stress-and-psychosocial-risks/view [accessed 2016-09-29] [WebCite Cache ID 6q505FkY0]

4. Schmidt A, Thews G. Autonomic Nervous System. In: Janig W, editor. Human Physiology, 2nd edition. New York, NY: Springer-Verlag; 1989:333-370.

5. Schneiderman N, Ironson G, Siegel SD. Stress and health: psychological, behavioral, and biological determinants. Annu Rev Clin Psychol 2005;1:607-628 [FREE Full text] [doi: 10.1146/annurev.clinpsy.1.102803.144141] [Medline: 17716101]

6. McEwen BS. Protective and damaging effects of stress mediators: central role of the brain. Dialogues Clin Neurosci 2006;8(4):367-381. [Medline: 17290796]

7. Grossi G, Perski A, Osika W, Savic I. Stress-related exhaustion disorder--clinical manifestation of burnout? a review of assessment methods, sleep impairments, cognitive disturbances, and neuro-biological and physiological changes in clinical burnout. Scand J Psychol 2015;56(6):626-636. [doi: 10.1111/sjop.12251] [Medline: 26496458]

8. Ho DY, Chan SF, Peng SQ, Ng AK. The dialogical self: converging East-West constructions. Cult Psychol 2001;7(3):393-408. [doi: $10.1177 / 1354067 X 0173008]$

9. Chan CL, Ng SM, Ho RT, Chow AY. East meets West: applying Eastern spirituality in clinical practice. J Clin Nurs 2006;15(7):822-832. [doi: 10.1111/j.1365-2702.2006.01649.x]

10. Dockett KH, Dudley-Grant GR, Bankart CP. Psychology and Buddhism: From individual to global community. New York, NY: Springer Science \& Business Media; 2003.

11. Chan CL, Palley HA. The use of traditional Chinese culture and values in social work health care related interventions in Hong Kong. Health \& Social Work 2005;30(1):76. [Medline: 15847241]

12. Wall RB. Tai Chi and mindfulness-based stress reduction in a Boston Public Middle School. J Pediatr Health Care 2005;19(4):230-237. [doi: 10.1016/j.pedhc.2005.02.006] [Medline: 16010262]

13. Wall RB. Teaching tai chi with mindfulness-based stress reduction to middle school children in the inner city: a review of the literature and approaches. InTai Chi Chuan 2008;52:166-172. [doi: 10.1159/000134297] [Medline: 18487896]

14. Griffith JM, Hasley JP, Liu H, Severn DG, Conner LH, Adler LE. Qigong stress reduction in hospital staff. J Altern Complement Med 2008;14(8):939-945 [FREE Full text] [doi: 10.1089/acm.2007.0814] [Medline: 18823261]

15. Skoglund L, Jansson E. Qigong reduces stress in computer operators. Complement Ther Clin Pract 2007; 13(2):78-84. [doi: 10.1016/j.ctcp.2006.09.003] [Medline: 17400142]

16. Germer CK, Siegel RD, Fulton PR. Mindfulness and psychotherapy. New York City: Guilford Publications; $2016: 128$.

17. Hyland PK, Lee RA, Mills MJ. Mindfulness at work: a new approach to improving individual and organizational performance. Ind Organ Psychol 2015;8(04):576-602. [doi: 10.1017/iop.2015.41]

18. Kabat-Zinn J. Mindfulness-based interventions in context: past, present, and future. Clin Psychol: Science and Practice 2003;10(2):144-156. [doi: 10.1093/clipsy.bpg016]

19. Marchand WR. Mindfulness-based stress reduction, mindfulness-based cognitive therapy, and Zen meditation for depression, anxiety, pain, and psychological distress. J Psychiatr Pract 2012 Jul;18(4):233-252. [doi: 10.1097/01.pra.0000416014.53215.86] [Medline: 22805898]

20. Baer RA, Carmody J, Hunsinger M. Weekly change in mindfulness and perceived stress in a mindfulness - based stress reduction program. J Clin Psychol 2012;68(7):755-765. [doi: 10.1002/jclp.21865] [Medline: 22623334]

21. Huppert FA, Johnson DM. A controlled trial of mindfulness training in schools: the importance of practice for an impact on well-being. J Posit Psychol 2010;5(4):264-274. [doi: 10.1080/17439761003794148]

22. Khoury B, Lecomte T, Fortin G, Masse M, Therien P, Bouchard V, et al. Mindfulness-based therapy: a comprehensive meta-analysis. Clin Psychol Rev 2013;33(6):763-771. [doi: 10.1016/j.cpr.2013.05.005] [Medline: 23796855]

23. Chiesa A, Serretti A. Mindfulness based cognitive therapy for psychiatric disorders: a systematic review and meta-analysis. Psychiatry Res 2011 May 30;187(3):441-453. [doi: 10.1016/j.psychres.2010.08.011] [Medline: 20846726]

24. Chiesa A, Serretti A. Mindfulness-based stress reduction for stress management in healthy people: a review and meta-analysis. J Altern Complement Med 2009;15(5):593-600. [doi: 10.1089/acm.2008.0495] [Medline: 19432513]

25. Bränström R, Kvillemo P, Brandberg Y, Moskowitz JT. Self-report mindfulness as a mediator of psychological well-being in a stress reduction intervention for cancer patients-A randomized study. Ann Behav Med 2010;39(2):151-161. [doi: 10.1007/s12160-010-9168-6] [Medline: 20177843]

26. Calvo RA, Peters D. Positive computing: technology for wellbeing and human potential. Cambridge: MIT Press; 2014. 
27. Christensen H, Hickie IB. Using e-health applications to deliver new mental health services. Med J Aust 2010;192(11):S53. [Medline: 20528711]

28. Burns JM, Davenport TA, Durkin LA, Luscombe GM, Hickie IB. The internet as a setting for mental health service utilisation by young people. Med J Aust 2010;192(11):S22. [Medline: 20528703]

29. Mani M, Kavanagh DJ, Hides L, Stoyanov SR. Review and evaluation of mindfulness-based iPhone apps. JMIR mHealth and uHealth 2015;3(3):e82 [FREE Full text] [doi: 10.2196/mhealth.4328] [Medline: 26290327]

30. Chittaro L, Vianello A. Computer-supported mindfulness: evaluation of a mobile thought distancing application on naive meditators. Int J Hum Comput Stud 2014;72(3):337-348. [doi: 10.1016/j.ijhcs.2013.11.001]

31. Calvo RA, Vella-Brodrick D, Desmet P, Ryan RM. Editorial for "positive computing: a new partnership between psychology, social sciences and technologists". Psychol Well Being 2016;6(1):10 [FREE Full text] [doi: 10.1186/s13612-016-0047-1] [Medline: 27441171]

32. Busch V, Magerl W, Kern U, Haas J, Hajak G, Eichhammer P. The effect of deep and slow breathing on pain perception, autonomic activity, and mood processing — an experimental study. Pain Med 2012;13(2):215-228 [FREE Full text] [doi: 10.1111/j.1526-4637.2011.01243.x] [Medline: 21939499]

33. Wollmann T, Abtahi F, Eghdam A, Seoane F, Lindecrantz K, Haag M, et al. User-centred design and usability evaluation of a heart rate variability biofeedback game. IEEE Access 2016;4:5531-5539. [doi: 10.1109/ACCESS.2016.2601882]

34. Khut GP, Muller L. Evolving creative practice: a reflection on working with audience experience in Cardiomorphologies. 2005 Presented at: Vital Signs: Creative Practice \& New Media Now; September 2005; Melbourne. [doi: 10.1109/mmul.2007.4298460]

35. Khut GP, Morrow A, Watanabe MY. The BrightHearts project: a new approach to the management of procedure-related paediatric anxiety. 2011 Presented at: OZCHI Workshop Call for Participation; November 2011; Canberra, Australia p. 17.

36. Morrow A, Yogul M, Khut PG. Brighthearts: development of a biofeedback controlled interactive artwork for the management of procedural pain and anxiety in children. Developmental Medicine \& Child Neurology 2014;56(14).

37. Wongsuphasawat K, Gamburg A, Moraveji N. You can't force calm: designing and evaluating respiratory regulating interfaces for calming technology. 2012 Presented at: In Adjunct proceedings of the 25th annual ACM symposium on User interface software and technology; October 7, 2012; Cambridge, MA p. 69-70. [doi: 10.1145/2380296.2380326]

38. Short AE, Ahern N, Holdgate A, Morris J, Sidhu B. Using music to reduce noise stress for patients in the emergency department: a pilot study. Music Med 2010 Jul 07;2(4):201-207.

39. Vidyarthi J, Riecke BE, Gromala D. Sonic Cradle: designing for an immersive experience of meditation by connecting respiration to music. 2012 Presented at: In Proceedings of the designing interactive systems conference; June 11, 2012; Newcastle, UK p. 408-417. [doi: 10.1145/2317956.2318017]

40. Shusterman R. Body consciousness: A philosophy of mindfulness and somaesthetics. Cambridge: Cambridge University Press; 2008.

41. Höök K, Jonsson M, Ståhl A, Mercurio J. Somaesthetic Appreciation Design. 2016 Presented at: the SIGCHI Conference on Human Factors in Computing Systems (CHI 16); May 7, 2016; San Jose, MA. [doi: 10.1145/2858036.2858583]

42. Zimmerman J, Forlizzi J, Evenson S. Research through design as a method for interaction design research in HCI. 2007 Presented at: the SIGCHI conference on Human factors in computing systems; April 29, 2007; San Jose, MA p. $493-502$. [doi: $10.1145 / 1240624.1240704]$

43. Lehrer PM, Vaschillo E, Vaschillo B. Resonant frequency biofeedback training to increase cardiac variability: rationale and manual for training. Appl Psychophysiol Biofeedback 2000;25(3):177-191. [Medline: 10999236]

44. Vaschillo EG, Vaschillo B, Lehrer PM. Characteristics of resonance in heart rate variability stimulated by biofeedback. Appl Psychophysiol Biofeedback 2006;31(2):129-142. [doi: 10.1007/s10484-006-9009-3] [Medline: 16838124]

45. Sutarto AP, Wahab MN, Zin NM. Heart Rate Variability (HRV) biofeedback: A new training approach for operator's performance enhancement. Journal of Industrial Engineering and Management 2010 Jun 22;3(1):176-198. [doi: 10.3926/jiem.2010.v3n1.p176-198]

46. Goodman LA. Snowball sampling. Ann Math Stat 1961:148-170. [doi: 10.1214/aoms/1177705148]

47. Kemper KJ, Danhauer SC. Music as therapy. Southern Medical Journal 2005;98(3):282-288. [doi: 10.1097/01.smj.0000154773.11986.39]

48. Salamon E, Kim M, Beaulieu J, Stefano GB. Sound therapy induced relaxation: down regulating stress processes and pathologies. Med Sci Monit 2003;9(5):RA96-RA101 [FREE Full text] [Medline: 12761468]

49. MacDougall R. The affective quality of auditory rhythm in its relation to objective forms. Psychol Rev 1903;10(1):15-36. [doi: $10.1037 / \mathrm{h} 0072426]$

50. Bauer C, Waldner F. Reactive music: when user behavior affects sounds in real-time. 2013 Presented at: CHI'13 Extended Abstracts on Human Factors in Computing Systems; April 27, 2013; Paris p. 739-744. [doi: 10.1145/2468356.2468488]

51. Karageorghis C, Jones L, Stuart DP. Psychological effects of music tempi during exercise. Int J Sports Med 2008;29(7):613-619. [doi: 10.1055/s-2007-989266] [Medline: 18050063]

52. Naghdi L, Ahonen H, Macario P, Bartel L. The effect of low-frequency sound stimulation on patients with fibromyalgia: a clinical study. Pain Res Manag 2015;20(1):e21-e27. 
53. Henry JA, Zaugg TL, Myers PJ, Schechter MA. Using therapeutic sound with progressive audiologic tinnitus management. Trends Amplif 2008;12(3):188-209 [FREE Full text] [doi: 10.1177/1084713808321184] [Medline: $\underline{18664499}$ ]

54. White JM. Music therapy: an intervention to reduce anxiety in the myocardial infarction patient. Clin Nurse Spec 1992;6(2):58-63. [Medline: 1617576]

55. Ellis P. Vibroacoustic sound therapy: case studies with children with profound and multiple learning difficulties and the elderly in long-term residential care. Stud Health Technol Inform 2003;103:36-42. [Medline: 15747903]

56. Augustin P, Hains AA. Effect of music on ambulatory surgery patients' preoperative anxiety. AORN journal 1996;63(4):750-758. [Medline: $\underline{8660020]}$

57. Nightingale F. Notes on Nursing: What it is and what it not. Cambridge: Cambridge University Press; 2010.

58. Alvarsson JJ, Wiens S, Nilsson ME. Stress recovery during exposure to nature sound and environmental noise. Int J Environ Res Public Health 2010;7(3):1036-1046. [doi: 10.3390/ijerph7031036]

59. Ulrich RS, Simons RF, Losito BD, Fiorito E, Miles MA, Zelson M. Stress recovery during exposure to natural and urban environments. J Environ Psychol 1991 Sep;11(3):201-230. [doi: 10.1016/s0272-4944(05)80184-7]

60. Kaplan S. The restorative benefits of nature: toward an integrative framework. J Environ Psychol 1995;15(3):169-182. [doi: 10.1016/0272-4944(95)90001-2]

61. Arduino. Arduino - Introduction URL: https://www.arduino.cc/en/Guide/Introduction [accessed 2016-11-12] [WebCite Cache ID 6lyHdVrxY]

62. Pure Data. Pure Data information URL: https://puredata.info/ [accessed 2016-11-12] [WebCite Cache ID 6ly2KkSIt]

63. Chen Y, Dangardt F, Osika W, Berggren K, Gronowitz E, Friberg P. Age-and sex-related differences in vascular function and vascular response to mental stress: longitudinal and cross-sectional studies in a cohort of healthy children and adolescents. Atherosclerosis 2012;220(1):269-274. [doi: 10.1016/j.atherosclerosis.2011.10.030] [Medline: 22078247]

64. Kaufman AS, Lichtenberger EO. Assessing adolescent and adult intelligence. US: John Wiley \& Sons; 2005.

65. Kirschbaum C, Pirke KM, Hellhammer DH. The 'Trier Social Stress Test'-a tool for investigating psychobiological stress responses in a laboratory setting. Neuropsychobiology 1993;28(1-2):76-81. [doi: 10.1159/000119004]

66. Chaudhry M, Ready R. Differential effects of test anxiety \& stress on the WAIS-IV. Journal of Young Investigators 2012;24(5):60-66.

67. Neupert SD, Miller LM, Lachman ME. Physiological reactivity to cognitive stressors: variations by age and socioeconomic status. Int J Aging Hum Dev 2006;62(3):221-235. [doi: 10.2190/17DU-21AA-5HUK-7UFG] [Medline: 16625938]

68. Barnes RF, Raskind M, Gumbrecht G, Halter JB. The effects of age on the plasma catecholamine response to mental stress in man. J Clin Endocrinol Metab 1982;54(1):64-69. [doi: 10.1210/jcem-54-1-64] [Medline: 7054219]

69. Bond A, Lader M. The use of analogue scales in rating subjective feelings. Br J Med Psychol 1974;47(3):211-218. [doi: 10.1111/j.2044-8341.1974.tb02285.x]

70. Lesage FX, Berjot S, Deschamps F. Clinical stress assessment using a visual analogue scale. Occup Med 2012;62(8):600-605. [doi: 10.1093/occmed/kqs 140] [Medline: 22965867]

71. Lesage FX, Berjot S. Validity of occupational stress assessment using a visual analogue scale. Occup Med 2011;61(6):434-436. [doi: 10.1093/occmed/kqr037] [Medline: 21505089]

72. Sztajzel J. Heart rate variability: a noninvasive electrocardiographic method to measure the autonomic nervous system. Swiss Med Wkly 2004;134(35-36):514-522. [Medline: 15517504]

73. Schubert C, Lambertz M, Nelesen RA, Bardwell W, Choi JB, Dimsdale JE. Effects of stress on heart rate complexity-a comparison between short-term and chronic stress. Biol Psychol 2009;80(3):325-332 [FREE Full text] [doi:

10.1016/j.biopsycho.2008.11.005] [Medline: 19100813]

74. Champaneri S, Wand GS, Malhotra SS, Casagrande SS, Golden SH. Biological basis of depression in adults with diabetes. Curr Diab Rep 2010;10(6):396-405. [doi: 10.1007/s11892-010-0148-9] [Medline: 20878274]

75. Carney RM, Freedland KE, Veith RC. Depression, the autonomic nervous system, and coronary heart disease. Psychosom Med 2005;67 Suppl 1:S29-S33. [Medline: 15953797]

76. Troubat N, Fargeas-Gluck MA, Tulppo M, Dugué B. The stress of chess players as a model to study the effects of psychological stimuli on physiological responses: an example of substrate oxidation and heart rate variability in man. Eur J Appl Physiol 2009;105(3):343-349. [doi: 10.1007/s00421-008-0908-2] [Medline: 18987876]

77. Abtahi F. Towards Heart Rate Variability Tools in P-Health: Pervasive, Preventive, Predictive and Personalized (Doctoral dissertation, KTH Royal Institute of Technology). Sweden: KTH Royal Institute of Technology; 2016.

78. Orsila R, Virtanen M, Luukkaala T, Tarvainen M, Karjalainen P, Viik J, et al. Perceived mental stress and reactions in heart rate variability - a pilot study among employees of an electronics company. Int J Occup Saf Ergon 2008;14(3):275-283. [doi: 10.1080/10803548.2008.11076767] [Medline: 18954537]

79. Pagani M, Lombardi F, Guzzetti S, Rimoldi O, Furlan RA, Pizzinelli PA, et al. Power spectral analysis of heart rate and arterial pressure variabilities as a marker of sympatho-vagal interaction in man and conscious dog. Circ Res 1986;59(2):178-193. [doi: 10.1161/01.res.59.2.178]

80. Bigger JT, Fleiss JL, Steinman RC, Rolnitzky LM, Kleiger RE, Rottman JN. Frequency domain measures of heart period variability and mortality after myocardial infarction. Circulation 1992;85(1):164-171. [Medline: 1728446] 
81. Camntech. Actiheart-overview URL: https://www.camntech.com/products/actiheart/actiheart-overview [accessed 2016-09-12] [WebCite Cache ID 6lyJqZ3jT]

82. Leroy G. Designing User Studies in Informatics. New York: Springer Science \& Business Media; 2011.

83. Britton WB, Lindahl JR, Cahn BR, Davis JH, Goldman RE. Awakening is not a metaphor: the effects of Buddhist meditation practices on basic wakefulness. Ann N Y Acad Sci 2014;1307(1):64-81. [doi: 10.1111/nyas.12279]

\section{Abbreviations \\ ANS: autonomic nervous system \\ MBSR: mindfulness-based stress reduction \\ HR: heart rate \\ HRV: heart rate variability}

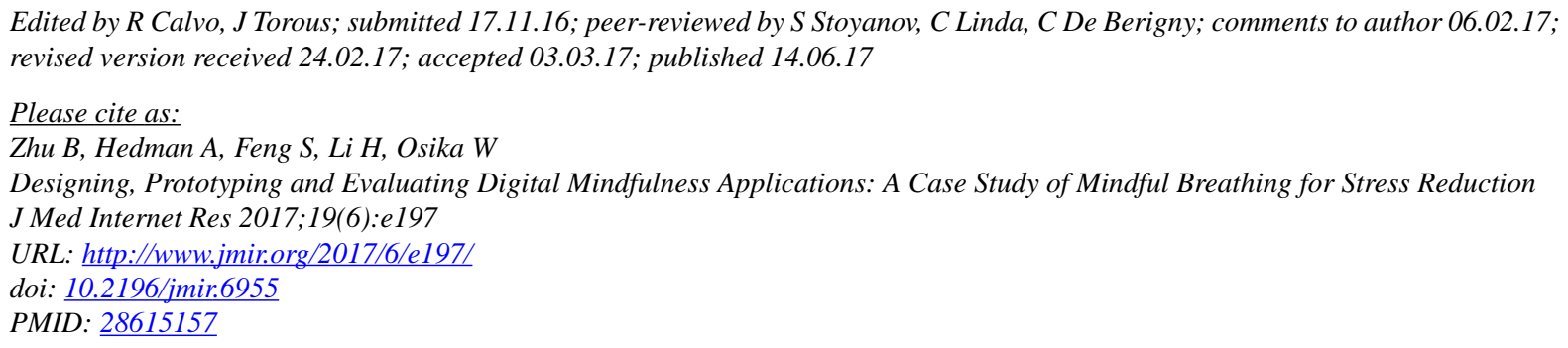

CBin Zhu, Anders Hedman, Shuo Feng, Haibo Li, Walter Osika. Originally published in the Journal of Medical Internet Research (http://www.jmir.org), 14.06.2017. This is an open-access article distributed under the terms of the Creative Commons Attribution License (https://creativecommons.org/licenses/by/4.0/), which permits unrestricted use, distribution, and reproduction in any medium, provided the original work, first published in the Journal of Medical Internet Research, is properly cited. The complete bibliographic information, a link to the original publication on http://www.jmir.org/, as well as this copyright and license information must be included. 